\title{
A INFLUÊNCIA DA COBERTURA MORTA SOBRE CARACTERÍSTICAS FÍSICAS E QUÍMICAS DE FRUTOS DA PINHA (Annona squamosa L.) ${ }^{1}$
}

\author{
JOSÉ CARLSON GUSMÃO DA SILVA², MODESTO ANTÔNIO CHAVES ${ }^{3}$, ABEL REBOUÇAS SÃO JOSÉ4, \\ TIYOKO NAIR HOJO REBOUÇAS ${ }^{4}$, JEAN FARLEY TEIXEIRA ALVES ${ }^{5}$
}

RESUMO - De forma geral a aplicação de resíduos vegetais ao solo tem efeitos benéficos sobre os nutrientes do solo, sob as suas condições físicas, sob a atividade biológica e sobre a performance das culturas. O objetivo principal deste trabalho foi avaliar, durante um ciclo produtivo, o efeito da cobertura de bagaço de cana, casca de café e palha de Buffel (Cenchrus ciliaris, L.), quanto ao seu efeito sobre características físicas e químicas do fruto da pinheira (Annona squamosa L.). O delineamento experimental foi o inteiramente casualizado, constando de cinco repetições, contendo duas plantas por parcela. Foram analisados: massa do fruto, massa da casca, massa das sementes e o número de sementes por fruto, o teor de sólidos solúveis e o pH da polpa. De modo geral, a presença da cobertura morta proporcionou incremento de massa aos frutos, o que promove aumento de receita, uma vez que, quanto maior for o fruto, melhor será seu preço. Não ocorreu aumento do $\mathrm{pH}$ da polpa, e o tratamento com casca de café proporcionou o maior teor de sólidos solúveis totais. Quanto às demais características, não foram encontradas diferenças.

Termos para indexação: Anonáceas, massa do fruto, $\mathrm{pH}$ da polpa, massa da casca.

\section{THE INFLUENCE OF MULCHING IN RELATION TO PHYSICAL AND CHEMICAL CHARACTERISTICS OF THE SUGAR APPLE (Annona squamosa L.)}

\begin{abstract}
The application of vegetal wastes to soil have a beneficial effects on soil nutrient, physical conditions, biological activities and on the culture performance, the main objective of this study was to evaluate three kinds of vegetable byproducts: sugar cane bagasse, coffee chaff, and Buffel straw, regarding to the effect on the physical and chemical characteristics of custard apple (Annona squamosa L.).The experimental design used completely randomid plots with five repplications, and two plants per plot. The total fruit mass, the peel mass, the seed mass per fruit were evaluated. The pulp level of soluble solids was measured, as well as its $\mathrm{pH}$. The presence of this mulching provided an increase in the fruit mass, thereby, increasing the commercial profit, as larger the fruit is, the greater the value per weight is. There was not a $\mathrm{pH}$ increase in the pulp, on the other hand the treatment using coffee chaff provided a greater level of soluble solids. Regarding to the other measured characteristics, no differences were found.
\end{abstract}

Index Terms: Annona, fruit pulp, $\mathrm{pH}$ of the pulp, chaff mass.

\section{INTRODUÇÃO}

Dentre as anonáceas cultivadas, a pinha, fruta-do-conde ou, ainda, ata (Annona squamosa L.), tem-se destacado, sendo seu consumo realizado quase que exclusivamente na forma de fruto in natura (São José, 1997). Segundo Kavati (1992), entre as anonáceas, a pinheira é a espécie que apresenta maior expressão econômica, ocorrendo a prática do seu cultivo em São Paulo e em vários estados nordestinos, onde a cultura vemse expandido de forma acentuada, notadamente nos perímetros irrigados. Essa expansão ocorre principalmente em função de suas características edafoclimáticas altamente favoráveis (Mosca et al., 1997).

O cultivo da pinha sob condições de irrigação, no Nordeste brasileiro, possibilita a colheita ao longo de todo o ano, sendo altamente tecnificada, tanto no que diz respeito ao uso intensivo de insumos (adubos, defensivos, etc.), como no emprego da mão-de-obra, uma vez que o manejo da poda permite escalonar a produção.

Considerando todos esses aspectos, a cultura da pinha, especialmente na região Nordeste, vem adquirindo grande importância do ponto de vista socioeconômico, pois é alto o valor necessário ao seu custeio. A movimentação desses recursos termina por impulsionar a economia regional em áreas extremamente carentes.

Sabe-se que a aplicação de resíduos vegetais ao solo tem efeitos benéficos sobre os nutrientes do solo, sob as suas condições físicas, sob a atividade biológica e sobre a performance das culturas (KANG et al., 1981; WADE \& SANCHEZ, 1983, HULUGALLE et al., 1986). Porém, de acordo com Tian et al. (1995), os efeitos dos resíduos vegetais sobre o solo e as culturas diferem, dependendo de sua decomposição e da taxa de transformação de nutrientes, os resíduos vegetais que se decompõem rapidamente, irão disponibilizar uma grande quantidade de nutrientes para as plantas nos estádios iniciais de crescimento, mas podem não ter efeito sobre as condições físicas do solo,

\footnotetext{
(Trabalho 114-05). Recebido em : 27-09-2005. Aceito para publicação em: 04-04-2007.

${ }^{2} \mathrm{Eng}^{\circ}$. Agr ${ }^{\circ}$., Ms, Rua C, 35, Vila Emurc, CEP 45.050-390, Vitória da Conquista-BA. Fone: (77) 422-2357. carlsongusmão@hotmail.com.

${ }^{3}$ Eng $^{\circ}$. Agrícola, Dr., Universidade Estadual do Sudoeste da Bahia, praça da Primavera, 40 - Primavera, CEP 45.700-000 Itapetinga-BA. Fone: (77) 261-8611.

${ }^{4}$ Eng $^{\circ} . \mathrm{Ag}^{\circ}$., Dr., Universidade Estadual do Sudoeste da Bahia, Estrada do Bem Querer, Km 4 - Cx. Postal 95, CEP 45.100-000 Vitória da ConquistaBA. Fone: (77) 424-8600.

${ }_{5}^{5}$ Discente do Curso de Agronomia da Universidade Estadual do Sudoeste da Bahia, Estrada do Bem Querer, Km 4 - Cx. Postal 95, CEP 45.100-000 Vitória da Conquista-BA. Fone: (77) 424-8600.
}

Rev. Bras. Frutic., Jaboticabal - SP, v. 29, n. 2, p. 287-291, Agosto 2007 
enquanto resíduos que se decompõem lentamente terão efeito exatamente oposto.

Para Cavalcanti (1993), a proteção do solo deve ser a principal preocupação do anonicultor. Essa preocupação iniciase no preparo da área com a manutenção da maior quantidade possível da matéria orgânica, aliada às práticas culturais conservacionistas, como capinas alternadas, renques de proteção e cobertura morta. Santos et al. (2001) enfocam a necessidade de pesquisa com base nas exigências hídricas e nutricionais da cultura.

Araújo (1999) destaca a importância do "mulching" ou cobertura morta nos pomares de pinha, sobretudo nas regiões semi-áridas, o que proporciona a manutenção da umidade em volta das plantas, exercendo, em parte, o controle de ervas daninhas, mantendo a temperatura do solo mais baixa e liberando gradualmente nutrientes para as plantas.

Também se sabe que a decomposição dos resíduos vegetais está relacionada com a relação $\mathrm{C} / \mathrm{N}$ em sua composição, além dos teores de lignina e polifenol. De forma a melhor predizer os efeitos dos resíduos vegetais sobre o solo e as culturas, Tian et al. (1995) propuseram um índice de qualidade para os resíduos vegetais, o qual pode ser usado para integrar os efeitos da relação $\mathrm{C} / \mathrm{N}$ e dos teores de lignina e polifenol.

Segundo Mota (1989), em muitas oportunidades, a temperatura do solo é de maior significado para a vida vegetal do que a temperatura do ar. Ainda de acordo com este autor, a significação ecológica da temperatura do solo é obviamente importante para aqueles que trabalham na agricultura. Uma temperatura do solo desfavorável durante a estação de crescimento, pode retardar ou mesmo arruinar as colheitas.

Nos trópicos, a diminuição da temperatura do solo e a preservação da umidade pelo uso de cobertura morta de resíduos culturais favorecem o desenvolvimento das plantas, uma vez que a seca e as altas temperaturas do solo podem afetar o desenvolvimento das sementes, diminuir a taxa de emergência, diminuir a espessura do tronco e o desenvolvimento das raízes, e diminuir a produção, de acordo Harrison-Murray e Lal (1979). O seu uso também pode afetar a disponibilidade de nutrientes pela melhora do microclima, segundo Tian et al. (1993).

Nas regiões semi-áridas brasileiras, predominam altas temperaturas associadas à baixa umidade do ar, de forma especial onde se localizam grande parte dos perímetros irrigados. Nesses casos, o emprego de cobertura morta pode incorporar benefícios aos cultivos irrigados, especialmente às fruteiras, contribuindo assim para melhor aproveitamento da água na manutenção e melhoria das características químicas daqueles solos, nas características físicas e químicas dos frutos da pinheira.

Segundo Reichardt (1978), a água é fator fundamental na produção vegetal. Sua falta ou excesso afeta de maneira decisiva o desenvolvimento das plantas, em regiões áridas e semi-áridas, o manejo correto implica práticas que promovem a economia de água como o uso de cobertura morta.

Em função do acima exposto, idealizou-se o presente trabalho com o objetivo de avaliar o efeito de diferentes tipos de material usado como a cobertura morta sobre características físicas e químicas do fruto e da planta da pinheira, (Annona squamosa L.).

\section{MATERIAIS E MÉTODOS}

Os ensaios de campo foram conduzidos na propriedade Rancho Alegre, no município de Anagé-BA, Latitude 14² $26^{\prime} 56^{\prime \prime}$ $\mathrm{S}$, Longitude $41^{\circ} 04^{\prime} 41^{\prime \prime}$ e altitude $330 \mathrm{~m}$. O período experimental foi de junho a outubro de 2003. O clima local pode ser classificado, segundo Koppen, como semí-árido muito quente, com chuvas de verão (Bswh'). O solo do local caracteriza-se como Cambissolo Háplico Tb, Eutrófico Trópicos, possuindo boa condição de drenagem.

Foram coletadas amostras de solo, de 0 a $20 \mathrm{~cm}$ de profundidade, para análises físicas e químicas. Essas análises foram realizadas antes da condução do experimento, a fim de se identificar o tipo de classe textural, quantificar os macronutrientes e determinar o $\mathrm{pH}$ do solo (Tabelas 1 e 2).

O espaçamento da cultura foi de 6,5 por $3,6 \mathrm{~m}$, tendo sido o plantio realizado em março de 1998. A irrigação utilizada foi do tipo localizada (microaspersão), tendo os aspersores a vazão de $30 \mathrm{~L} / \mathrm{h}$, fornecendo água para duas plantas simultaneamente. Foi aplicada uma lâmina bruta de água de $6 \mathrm{~mm}$ por dia, sempre no período noturno (Araújo Filho et al., 1998).

O experimento constou de 4 tratamentos (T1-bagaço de cana, T2-casca de café, T3-palha de Buffel e T4-sem cobertura morta), com cinco repetições, em delineamento inteiramente casualizado. Foram avaliadas as massas da polpa, da casca, das sementes e do fruto. Mediram-se também o pH e o teor de sólidos solúveis da polpa.

Conforme análise química inicial feita pelos técnicos do DEAS/UESB, na adubação, foram usados $400 \mathrm{~g}$ de superfosfato simples incorporado a $10 \mathrm{~cm}$ de profundidade, na projeção da copa, no lado voltado para o microaspersor. Em cobertura, foram aplicados $30 \mathrm{~g}$ de FTE Br 12 (micronutrientes), e $480 \mathrm{~g}$ de uréia e $462 \mathrm{~g}$ de cloreto de potássio (dividido em seis aplicações de $80 \mathrm{~g}$ e $77 \mathrm{~g}$, respectivamente) intercalados a cada 20 dias, durante o ciclo produtivo, ou seja, cinco meses, aproximadamente, da poda até a colheita. Também foram aplicados $20 \mathrm{~L}$ de esterco antes da distribuição da cobertura morta.

Para a determinação das massas, foram selecionados ao acaso 5 frutos por planta, totalizando 10 frutos por parcela e utilizou-se a balança semi-analítica marca GEAKA. Os mesmos foram colhidos após atingir o ponto de maturação fisiológica (ponto de colheita), determinado pelo afastamento dos carpelos e coloração verde-amarelada dos tecidos intercarpelares. Em todas as plantas, foi mantida uma carga de 25 frutos, uma vez que a quantidade de frutos tem influência sobre as massas dos mesmos.

$\mathrm{O} \mathrm{pH}$ foi determinado usando o Phmetro modelo Q400A, fabricado pela Quimis Aparelhos Científicos Ltda. As leituras foram feitas diretamente do aparelho, que possui compensação de temperatura, tendo sido calibrado e operado conforme recomendação do seu manual. Na medição do teor de sólidos solúveis (BRIX), utilizou-se um refratômetro de mão marca ATAGO, modelo N-1a, procedendo-se a leitura diretamente do 
aparelho, que possui escala de $0-30^{\circ}$ Brix.

\section{RESULTADOS E DISCUSSÃO}

\subsubsection{Média das massas dos frutos e percentual em relação à testemunha}

Os resultados referentes à média das massas dos frutos e o percentual em relação à testemunha, dos quatro tratamentos, encontram-se na Tabela 3. Com relação à massa, os frutos colhidos no tratamento palha de Buffel foram os que apresentaram o maior valor absoluto, $359,68 \mathrm{~g}$, sendo estatisticamente superior à testemunha, não diferindo, entretanto, das demais coberturas. Embora não tenha sido possível detectar diferença estatística no que se refere aos demais tratamentos, a casca de café e a palha de cana apresentaram resultados intermediários, e a testemunha foi a que obteve a menor média, $330,40 \mathrm{~g}$, o que nos leva a inferir que todo tratamento com cobertura morta aumentou a massa dos frutos. No caso deste experimento, houve mais que $7 \%$ de aumento na massa dos frutos, fato este que proporciona melhor preço de comercialização, uma vez que, quanto maior o fruto, melhor será o seu valor, conforme demonstram Kavati e Piza Júnior (1997), que os tipos superiores correspondem a um acréscimo de até $80 \%$ no preço da comercialização (Tabela 4).

A média da massa entre os tratamentos foi de $350,34 \mathrm{~g}$, bem superior às encontradas por Holschuh et al. (1987), com 193,38 g, em trabalho desenvolvido no Estado da Paraíba e semelhante aos obtidos por Dantas et al. (1991), para as seleções (IPA-2; $; ; 8 ; 11 ; 13 ; 15 ; 18 ; 19 ; 20$ e 21), que encontraram massas entre 300 e $400 \mathrm{~g}$ em avaliações realizadas nos Estados de Alagoas e Pernambuco, provavelmente em condições edafoclimáticas um pouco diferentes deste experimento. Essa média evidencia, a princípio, um melhor resultado dos tratamentos em relação à testemunha.

\subsubsection{Média das massas das cascas e percentuais em relação à massa total e testemunha}

Quanto à massa das cascas (Tabela 5), tanto na análise de variância como no teste de comparação de médias - teste Tukey, a 5(\%) de probabilidade - , os resultados demonstraram que os efeitos dos tratamentos foram semelhantes aos ocorridos com a massa dos frutos, ou seja, superiores para cobertura com buffel e iguais para bagaço de cana e casca de café, demonstrando haver correlação entre as características avaliadas, ou seja, quanto maior a massa do fruto, maior a massa da casca.

A média geral de massa das cascas foi de $185,88 \mathrm{~g}$, este valor é maior que os encontrados por Holschuh et al. (1987), Dantas et al. (1991) e Dias et al. (2003), que relataram massa de cascas entre 77 a 128 g. Quando se compara o percentual, em relação à massa dos frutos, encontramos valores em torno de $53 \%$, bem próximos aos obtidos por Holschuh et al. (1987) e Dias et al. (2003), que encontraram percentuais de 52,95 e $51,92 \%$, respectivamente. Em relação à testemunha, de maneira análoga à massa de frutos, a massa de cascas apresentou aumento em todos os tratamentos, num percentual de 13 a $15 \%$.

\subsubsection{Massa e percentual de polpa}

Não se observou nenhuma diferença significativa ( $p<0,05$, pelo teste de Tukey) para as massas de polpa, entre os diferentes tratamentos avaliados (Tabela 6). Os valores das médias foram bastante semelhantes para os três tipos de cobertura, situandose em torno de $138 \mathrm{~g}$, valor um pouco maior que o obtido na testemunha, que foi de aproximadamente $134 \mathrm{~g}$. Esses valores foram maiores que os encontrados por Holschuh et al. (1987) e Dantas et al. (1991), e inferiores aos de Maia et al. (1986); por outro lado, resultados semelhantes foram obtidos por Silva (2000) e Dias et al. (2003), ambos sob condição de irrigação, e na região sudoeste da Bahia, a mesma microregião onde o presente trabalho foi conduzido.

\subsubsection{Massa e número de sementes}

No caso dos valores médios de massa e número de sementes (Tabela 7), não foi possível detectar diferença estatística entre os tratamentos, pelo teste de Tukey $(\mathrm{p}<0,05)$.

Considerando o percentual da massa de sementes em relação à massa total do fruto, encontramos resultados semelhantes aos de Maia et al. (1986), que foi de 7,6\%, e superior aos de Holschuh et al. (1987), com 5,66\%, e aos de Silva (2000), com 6,47\%, e inferiores aos obtidos por Dias et al. (2003), que encontraram para a mesma característica percentual de 9,5\%.

\subsection{5 $\mathrm{pH}$ da polpa e brix}

A Tabela 8 mostra as médias do $\mathrm{pH}$ da polpa para cada tratamento, bem como o resultado do teste de comparação das médias de tratamento. Observou-se que, na presença de cobertura morta, o pH não apresentou alteração, ou seja, a presença de cobertura morta não interferiu nesta característica.

No caso do teor de sólidos solúveis (Brix) na polpa (Tabela 8), observou-se que, em todos os tratamentos, o teor aumentou em relação à testemunha. Contudo, apenas no tratamento em que houve cobertura do solo com casca de café, houve diferença significativa em termos estatísticos ( $\mathrm{P}<0,05$ pelo teste de Tukey).

Embora não tenham sido feitos testes de análise sensorial, certamente estes valores maiores de Brix obtidos com o uso de cobertura morta, principalmente com o uso da cobertura da casca de café, irão contribuir no aspecto de palatabilidade dos frutos, uma vez que indicam a quantidade de açúcar presente na polpa.

\subsubsection{Análise química da cobertura}

Através da análise química, realizada conforme Silva e Queiroz (2002), observou-se que o bagaço de cana possui alto teor de lignina, bem como alta relação $\mathrm{C} / \mathrm{N}$ (Tabela 9), seguida pela a palha de capim e pela casca de café, por ordem decrescente de teores desses elementos componentes da parede celular.

Esses resultados indicam a casca de café, dentre as demais coberturas, como o melhor material para essa finalidade, em função da sua melhor relação carbono/nitrogênio $(\mathrm{C} / \mathrm{N})$, (Tabela 9), seguido pela palha de Buffel, entre os materiais avaliados. Segundo Costa (1985), citado por Matos et al. (1998), em trabalho com compostagem de resíduos vegetais, desde que 
o material palhoso possua relação $(\mathrm{C} / \mathrm{N})$ próxima de 30:1, este terá boas condições de decomposição, o que favorece, também, a liberação de nutrientes para o solo, além do efeito protetor.

TABELA 1 - Análise física do solo da área experimental. Laboratório UESB.

\begin{tabular}{|c|c|c|c|c|c|c|c|}
\hline \multicolumn{3}{|c|}{ Frações da amostra total (\%) } & \multicolumn{4}{|c|}{ Composição granulométrica da TFSA (\%) } & \multirow[b]{2}{*}{$\begin{array}{l}\text { Classe } \\
\text { Textural }\end{array}$} \\
\hline $\begin{array}{c}\text { Calhaus } \\
200-20 \\
(\mathrm{~mm})\end{array}$ & $\begin{array}{l}\text { Casc. } \\
20-2 \\
(\mathrm{~mm}) \\
\end{array}$ & $\begin{array}{l}\text { TFSA } \\
<2 \mathrm{~mm}\end{array}$ & $\begin{array}{c}\text { Areia grossa } 2- \\
0,20 \mathrm{~mm}\end{array}$ & $\begin{array}{c}\text { Areia fina } \\
0,20-0,05(\mathrm{~mm})\end{array}$ & $\begin{array}{l}\text { Silte } 0,05-0,002 \\
(\mathrm{~mm})\end{array}$ & $\begin{array}{c}\text { Argila } \\
<0,002 \\
(\mathrm{~mm})\end{array}$ & \\
\hline 0 & 0 & 100 & 345 & 191 & 110 & 354 & Argila Arenosa \\
\hline 0 & 0 & 100 & 337 & 179 & 120 & 364 & Argila Arenosa \\
\hline 0 & 0 & 100 & 319 & 180 & 127 & 374 & Argila Arenosa \\
\hline 0 & 0 & 100 & 295 & 195 & 151 & 359 & Argila Arenosa \\
\hline 0 & 0 & 100 & 309 & 199 & 122 & 370 & Argila Arenosa \\
\hline 0 & 0 & 100 & 321 & 189 & 126 & 364 & Argila Arenosa * \\
\hline
\end{tabular}

* Valores médios

TABELA 2 - Análise química do solo da área experimental. Laboratório UESB.

\begin{tabular}{|c|c|c|c|c|c|c|c|c|c|c|c|c|c|}
\hline \multirow{2}{*}{ Identificação } & \multirow{2}{*}{$\begin{array}{c}\mathrm{pH} \\
\left(\mathrm{H}_{2} 0\right)\end{array}$} & \multirow{2}{*}{$\begin{array}{c}\mathrm{mg} / \mathrm{dm}^{3} \\
\mathrm{P}\end{array}$} & \multicolumn{9}{|c|}{$\mathrm{cmol}_{\mathrm{c}} / \mathrm{dm}^{3}$ de solo } & \multicolumn{2}{|c|}{$\%$} \\
\hline & & & $\mathrm{K}^{+}$ & $\mathrm{Ca}^{++}$ & $\mathrm{Mg}^{++}$ & $\mathrm{Al}^{++1}$ & $\mathrm{H}^{+}$ & $\mathrm{Na}^{+}$ & S.B. & $\mathrm{t}$ & $\mathrm{T}$ & $\mathrm{V}$ & MO \\
\hline $50 \mathrm{~cm}$ do tronco & 5,8 & 72 & 1,58 & 7,1 & 1,8 & 0,0 & 2,9 & 0,0 & 10,5 & 10,5 & 13,4 & 78 & 2,7 \\
\hline $100 \mathrm{~cm}$ do tronco & 7,2 & 9 & 1,42 & 5,0 & 2,8 & 0,0 & 1,5 & 0,0 & 9,2 & 9,2 & 10,7 & 86 & 2,2 \\
\hline $150 \mathrm{~cm}$ do tronco & 7,6 & 4 & 0,76 & 5,2 & 3,7 & 0,0 & 1,2 & 0,0 & 9,7 & 9,7 & 10,9 & 89 & 1,7 \\
\hline Média & 6,6 & 24 & 1,32 & 5,0 & 2,7 & 0,0 & 1,8 & 0,0 & 9,0 & 9,0 & 10,8 & 83 & 2,2 \\
\hline
\end{tabular}

TABELA 3 - Médias da massa dos frutos de pinha, em completo estágio de maturação, por tratamento.

\begin{tabular}{llc}
\hline \multicolumn{1}{c}{ Tratamentos } & Massa do Fruto $(\mathrm{g})$ & Percentual em relação à testemunha \\
\hline Bagaço de cana & $354,55 \mathrm{ab}$ & 107,31 \\
Casca de café & $356,75 \mathrm{ab}$ & 107,97 \\
Palha de Buffel & $359,68 \mathrm{a}$ & 108,86 \\
Testemunha & $330,40 \mathrm{~b}$ & 100,00 \\
\hline Média Geral & 350,34 & -- \\
\hline DMS & 27,41 & -- \\
* Médias seguidas pela mesma letra na coluna não diferem entre si, pelo \\
\multicolumn{2}{l}{ teste de Tukey, a 5\% de probabilidade. }
\end{tabular}

TABELA 4 - Índice de variação de preços em função do tipo da fruta

\begin{tabular}{cc}
\hline Tipo & Indice (\%) \\
\hline 9 & 100 \\
\hline 12 & 96 \\
\hline 15 & 75,5 \\
\hline 18 & 50 \\
\hline 21 & 30 \\
\hline 24 & 20 \\
\hline
\end{tabular}

Fonte: CEAGESP, citado por (KAVATI; PIZA JÚNIOR, 1997).

TABELA 5 - Médias da massa das cascas de pinha, em completo estádio de maturação, para cada tratamento, e percentuais em relação à massa total e testemunha.

\begin{tabular}{lccc}
\hline \multicolumn{1}{c}{ Tratamentos } & Massa da Cascas $(\mathrm{g})$ & Percentual em relação à massa total & Percentual em relação à testemunha \\
\hline Bagaço de cana & $190,16 \mathrm{ab}$ & 53,63 & 113,43 \\
Casca de café & $191,95 \mathrm{ab}$ & 53,80 & 114,50 \\
Palha de Buffel & $193,76 \mathrm{a}$ & 53,87 & 115,69 \\
Testemunha & $167,64 \mathrm{~b}$ & 50,74 & 100,00 \\
\hline Média Geral & 185,88 & -- & -- \\
\hline DMS & 25,13 & -- & --
\end{tabular}

* Médias seguidas pela mesma letra na coluna não diferem entre si, pelo teste de Tukey, a 5\% de probabilidade.
TABELA 6 - Médias das massas de polpa e respectivos percentuais, para os frutos da pinheira, em completo estádio de maturação. 2003.

\begin{tabular}{llr}
\hline \multicolumn{1}{c}{ Tratamentos } & Massa da polpa $(\mathrm{g})$ & \% da massa \\
\hline Bagaço de cana & $138,58 \mathrm{a}$ & $39,01 \mathrm{a}$ \\
Casca de café & $138,31 \mathrm{a}$ & $38,77 \mathrm{a}$ \\
Palha de Buffel & $138,34 \mathrm{a}$ & $38,46 \mathrm{a}$ \\
Testemunha & $134,93 \mathrm{a}$ & $40,08 \mathrm{a}$ \\
\hline Média Geral & 137,54 & 39,08 \\
\hline DMS & 11,25 & 4,03 \\
\hline
\end{tabular}

* Médias seguidas pela mesma letra na coluna não diferem entre si, pelo teste de Tukey, a $5 \%$ de probabilidade.

TABELA 7 - Média e percentual das massas e do número de sementes dos frutos da pinheira por ocasião da maturação. 2003.

\begin{tabular}{llll}
\hline \multicolumn{1}{c}{ Tratamentos } & Massa de Sementes $(\mathrm{g})$ & $\%$ & Número de Sementes \\
\hline Bagaço de cana & $25,82 \mathrm{a}$ & 7,28 & $63,00 \mathrm{a}$ \\
Casca de café & $26,48 \mathrm{a}$ & 7,42 & $65,10 \mathrm{a}$ \\
Palha de Buffel & $27,58 \mathrm{a}$ & 7,66 & $64,27 \mathrm{a}$ \\
Testemunha & $27,79 \mathrm{a}$ & 8,41 & $66,29 \mathrm{a}$ \\
\hline Média Geral & 26,92 & 7,69 & 64,66 \\
\hline DMS & 2,73 & -- & 5,88 \\
\hline
\end{tabular}

* Médias seguidas pela mesma letra na coluna não diferem entre si, pelo teste de Tukey, a 5\% de probabilidade.

TABELA 8 - Médias do pH e do teor de sólidos solúveis (Brix) da polpa dos frutos de pinha para cada tratamento.

\begin{tabular}{lll}
\hline TRATAMENTO & PH * & BRIX* \\
\hline Bagaço de cana & $5,5 \mathrm{a}$ & $25,18 \mathrm{~b}$ \\
Casca de café & $5,8 \mathrm{a}$ & $27,71 \mathrm{a}$ \\
Palha de Buffel & $5,4 \mathrm{a}$ & $25,36 \mathrm{~b}$ \\
Testemunha & $5,5 \mathrm{a}$ & $25,10 \mathrm{~b}$ \\
\hline DMS & 0,62 & 2,58 \\
\hline
\end{tabular}

* Médias seguidas da mesma letra na coluna não diferem entre si, pelo teste de Tukey, a $5 \%$ de probabilidade.

Rev. Bras. Frutic., Jaboticabal - SP, v. 29, n. 2, p. 287-291, Agosto 2007 
TABELA 9 - Médias percentuais dos teores de lignina e celulose e a relação carbono/nitrogênio $(\mathrm{C} / \mathrm{N})$ dos tratamentos.

\begin{tabular}{lccc}
\hline Tratamentos & Lignina & Celulose & Relação C/N \\
\hline Bagaço de cana & 26,38 & 22,92 & $86: 1$ \\
Casca de café & 13,03 & 31,01 & $28: 1$ \\
Palha de Buffel & 6,05 & 36,51 & $42: 1$ \\
\hline Média geral & 15,15 & 30,14 & $52: 1$ \\
\hline
\end{tabular}

\section{CONCLUSÕES}

Os resultados obtidos permitem concluir que os tipos de cobertura morta utilizados interferiram de formas distintas sobre características do fruto, para as condições edafoclimáticas locais:

1-De forma geral, os tratamentos com cobertura morta promoveram incremento de massa aos frutos e às cascas.

2-O maior teor de sólidos solúveis foi verificado no tratamento com casca de café.

3- A massa da polpa e seu percentual, a massa e o número de sementes e o $\mathrm{pH}$ da polpa dos frutos, não foram influenciados pela presença de cobertura morta.

\section{REFERÊNCIAS}

ARAÚJO FILHO, G. C.; ANDRADE, O. M. S.; SA, F.T. Instruções técnicas para o cultivo da ateira. Fortaleza: Embrapa, 1998. p.1-9. (Instrução Técnica, 1)

DANTAS, N. P.; BEZERRA, J. E. F.; PEDROSA, A. C.; LEDERMAN, I. E. Características físico-químicas de frutos de pinheira (Annona squamosa L.) oriundos de Pernambuco e Alagoas. Revista Brasileira de Fruticultura, Jaboticabal, v. 13, n.1, p.11-116, 1991.

DIAS, N.O., MATSUMOTO, S.N.; REBOUÇAS, T.N.H., VIANA, A.E.S.; JOSÉ, A.R.S.; SOUZA, I.V.B. Influência da poda de produção em ramos de diferentes diâmetros no desenvolvimento vegetativo e reprodutivo da pinheira (Annona squamosa L.). Revista Brasileira de Fruticultura. Jaboticabal, v.25, n.1, p.103-103, 2003.

HARRISON-MURRAY, R.S.; LAL, R. High soil temperature and response of maize to mulching in lowland humid tropics. In: LAL, R.; GREENLAND, D.J. Soil physical properties and crop production in the tropics, Chichester: Wiley, p.285-304, 1979.

HOLSCHUH, H. S.; NARAIN, N.; BORA, P. S.; VASCONSELOS, M. A. da S.; SANTOS, C. M. G. dos. Caracterização física de frutos de pinha oriundos do trópico, semi-árido da Paraíba. In: CONGRESSO BRASILEIRO DE FRUTICULTURA, 9., 1987, Campinas. Anais... Campinas: Sociedade Brasileira de Fruticultura, 1988.p.669-673.

HULUGALLE, N. ;LAL, R.; TERKUILE, C.H.H. Amelioration of soil physical properties by Mucuna after mechanized land clearing of a tropical rainforest. Soil Science, Madison, n. 141, p. 219-224, 1986.

KANG, B.T.; SIPKENS, L.; WILSON, G.F.; NANGIU, D. Leucaena [leucaena leucocephala (Lal) de Wit] prunings as nitrogen sources for maize (Zea mays L.) Fertilization Research, Holanda, n. 2, p.279-287, 1981.

KAVATI, R. O cultivo da atemóia. Campinas: CATI, 1992. p.3970.

KAVATI, R.; PIZA Jr., C. de T. Formação e manejo do pomar de fruta-do-conde, atemóia e cherimóia. In: SÃO JOSÉ, A.R.; SOUZA, I.V.B.; MORAIS, O.M.; REBOUÇAS, T. N. H. Anonáceas: produção e mercado. Vitória da Conquista: UESB/DFZ, 1997. p.75-83.

MAIA, G.A.; MESQUITA FILHO, J.A.; BARROSO, M.A.T.; FIGUEIREDO, R.W. Características físicas e químicas da ata. Pesquisa Agropecuária Brasileira, Brasília, n. 21, v.10, p.1073-1076, out., 1986.

MATOS, A.T. de; VIDIGAL, S.M.: SEDIYAMA, M.A.N.; GARCIA, N.C.P; RIBEIRO, M.F. Compostagem de alguns resíduos orgânicos utilizando-se de águas residuárias da suinocultura como fonte de nitrogênio. Revista Brasileira de Engenharia Agrícola e Ambiental, Campina Grande,v.2,n.2,p.199-203,1998.Disponível em: http:/ www.agriambi.com.br/revista/v2n2/199>. Acesso em: 15 jan. 2004.

MOSCA, J.L. et al. Physical, Physical-Chemical and chemical changis during growth and maturation of sugar apple (Annona squamosa L.). In: CONGRESSO INTERNACIONAL DE ANONACEAS; 1997; Chapingo. Anais...

MOTA, F. S. Meteorologia agrícola. 7. ed. São Paulo: Nobel, 1989.376p.

REICHARDT, K. Aágua na produção agrícola. São Paulo: McGraw-hill, 1978.

SANTOS, E.D.P. dos et al. Comportamento vegetativo e produtivo da pinheira sob níveis de água. Anais do CPA em Manejo de Solo e Água, Areia, Paraiba, v.23, 2001.

SÃO JOSÉ, A. R. Aspectos gerais das anonáceas no Brasil. In: SÃO JOSÉ, A.R. et al. (Eds.). Anonáceas: produção e mercado. Vitória da Conquista: UESB, 1997.

SILVA, D. J.; QUEIROZ, A. C. Análise de alimentos, métodos químicos e biológicos. 3. ed. Viçosa: UVF, 2002.

SILVA, A. C. da. Épocas de poda e métodos de polinização na produção da pinheira (Annona squamosa L.). 2000. $101 \mathrm{f}$. Dissertação (Mestrado em Fruticultura) - Escola de Agronomia, Universidade Federal da Bahia, Cruz das Almas, 2000.

TIAN, G.; BRUSSAARD, L.; KANG, B.T. An index for assessing the quality of plant residues and evaluating their effects on soil and crop in the (sub-)humid tropics. Applied Soil Ecology, Amsterdan, n.2, p.25-32, 1995.

TIAN, G.; KANG, B.T.; BRUSSAARD, L. Cobertura morta effect of plant residues with chemically contrasting compositions on maize growth and nutrient accumulation. Plant and Soil, Dordrecht, n.153, p.179-187, 1993.

WADE, W.K.; SANCHEZ, P.A. Mulching andgreen manure application for continuos crop production in the Amazon basin. Agronomy Journal, Madison, n.75, p.39-45, 1983. 